\title{
Política, prisión y achaques del viejo Quevedo (1640-1645): dos rebeliones, dos memoriales y un panegírico ${ }^{1}$
}

\author{
M. ${ }^{\text {a }}$ Soledad Arredondo \\ Universidad Complutense \\ Universidad Complutense de Madrid \\ Edificio D \\ Plaza Menéndez Pelayo, s / n \\ Campus de Moncloa \\ 28040 Madrid \\ msarredo@filol.ucm.es \\ [La Perinola, (Issn: 1138-6363), 21, 2017, pp. 131-149] \\ DOI: $10.15581 / 017.21 .131-149$
}

El violento arresto de Quevedo en diciembre de 1639, la prisión en León y sus duras condiciones marcaron los últimos años de la vida del escritor, tanto física como sicológicamente. Incluso cuando dicha prisión parecía suavizarse, el recuerdo de la humillante detención y del primer año de encarcelamiento se refleja en muchos de sus textos, y se recoge minuciosamente en los memoriales ${ }^{2}$ dedicados al conde-duque y al rey, y en su epistolario, que relata los dolorosos detalles a diferentes destinatarios. Todavía aparecen, por ejemplo, en la dedicatoria a Juan de Chumacero de La caída para levantarse ${ }^{3}$, firmada en 1644. Sin embargo, ello no impidió que nuestro autor desarrollara gran actividad literaria en León, especialmente a partir de $1641^{4}$, buena parte de la cual es obra política, si entendemos por tal la encaminada a lavar o mejorar su imagen, es decir, la del hombre público, caballero de Santiago y secretario del rey, detenido por motivos políticos: "por causa grave», según palabras de Felipe IV, y por ser traidor al gobierno, según el conde-duque de Olivares ${ }^{5}$. En este sentido, las últimas obras de Quevedo, como los opúsculos sobre las rebeliones de catalanes y portugueses, obedecen a su conocido interés por la política, o a su propia política

1. Este trabajo forma parte del proyecto de investigación «De la biblioteca particular al canon literario en los Siglos de Oro (xVI y xVII)» I y II, ref. FFI 2012-35894.

2. Cito los dos memoriales por la edición de Rey, 2015.

3. Cito por la edición de Nider, 1994.

4. Ver Jauralde, 1982.

5. Ver Elliott, 1972, y Jauralde, 1999, pp. 759-776, con amplia bibliografía a la que remito. 
personal; esta última estaba encaminada a obtener la libertad, el perdón real, la recuperación de su honra y de su hacienda, y a dar muestras de erudición y resignación ante la adversidad. Sean de uno u otro género, todas esas obras llevan la huella de la traumática detención y sus secuelas, empezando por las que redactó en prisión, aunque todavía persistan las dificultades de datación e interpretación de las mismas ${ }^{6}$.

Las actitudes de ese Quevedo de senectute ${ }^{7}$ y su «agónica situación final» ${ }^{8}$ se distinguen de las del joven poeta satírico, y también de las del cortesano influyente que escribió en 1635 la Carta al rey de Francia. Probablemente sus ideas políticas permanecieron incólumes en lo esencial, pero la expresión escrita de las mismas fue cauta y variable, dependiendo del destinatario y del género que cultivara9: como prueba de esa prudencia basta recordar que en prisión empleó seudónimos para la Respuesta al manifiesto del Duque de Berganza ${ }^{10}$ (Alonso Pérez Liñares), La Rebelión de Barcelona ni es por el güevo ni es por el fuero ${ }^{11}$ (Antonio Martínez Montejano) y algunas cartas ${ }^{12}$ dirigidas a los jesuitas desde «Pamplona» por «Fray Ignacio Pérez».

En esos años de prisión, enfermedad y alejamiento de la corte las opiniones de Quevedo oscilaron de modo desconcertante en ocasiones -sobre todo en lo que atañe al valido de Felipe IV-, oportunista en otras $^{13}$, llegando incluso a servirse de lecturas que Olivares podía apreciar para apelar a la grandeza del perdón ${ }^{14}$. Sus declaraciones, y sus silencios, sobre cuestiones generales o particulares evolucionan según los peligrosos cambios políticos que le tocó vivir, como había ocurrido en etapas anteriores, desde el cambio de régimen que comentó en Grandes anales de quince días ${ }^{15}$, hasta su detención en 1639. Esos peligros, que tanto hirieron y desconcertaron al anciano escritor -y la edad se convierte en un poderoso argumento en los dos memoriales citados-, no le afectaron en exclusiva, porque la incertidumbre tras la caída del condeduque en 1643 debió de ser general, como dice Quevedo en carta a su amigo Sandoval, en noviembre de 1644:

6. Ver Fasquel, 2015.

7. Según la terminología que consagró Juan Manuel Rozas para Lope.

8. Así llama Alfonso Rey, en Obras completas en prosa, vol. VI, 2015, p. XLIV, a estos últimos años en su edición de los dos memoriales.

9. Para las preferencias quevedianas por ciertos temas, en prosa o verso, ver Ettinghausen, 1995, p. 253.

10. Cito por la edición de Arredondo, 2005.

11. Cito por la edición de Urí, 2005.

12. Cito por la edición de Crosby, 2005.

13. Jauralde, 1982 , p. 160 , se refiere al «descarado uso que hace de su pluma como instrumento de sus pretensiones».

14. Crosby, 1997.

15. Me he referido a esta obra y a la manipulación de los tiempos por parte de Quevedo en «De la antigüedad gloriosa al presente enfermo: hermosas palabras de Quevedo y Palafox para el tiempo y la política», ponencia en el Coloquio Internacional Le prèsent fabriqué, celebrado en París, febrero de 2014 (en prensa). 
Créame v. m., señor don Sancho, que no hay quien sepa dónde va la corriente de las cosas ni de dónde viene, tan rebalsado va todo. Unos sospechan que el Conde no ha acabado; téngolo por necedad medrosa (p. 154).

En efecto, Quevedo no era el único en manifestar dudas y perplejidad, porque también el cronista José Pellicer, uno de los hombres mejor informados de su tiempo, se refiere a los muchos rumores que circulaban: desde la caída del valido, de la que no informa hasta julio de $1643^{16}$; hasta la prohibición de que saliera de Toro, en junio de 1644, porque «está algo más que detenido» (p. 523); o la prisión del influyente Protonotario Villanueva, en septiembre de 1644, en un aviso precedido de un anuncio ponderativo - «No son pocas las novedades que han sucedido en estos ocho días. Sea la primera la prisión de don Gerónimo Villanueva...»- y cerrado con una conclusión elocuente: «Raro exemplo para un Ministro que manejó el gobierno de Reinos tantos» (p. 542); así como la prisión del Duque de Medina Sidonia, tratada en varios avisos hasta junio de 1644, cuando el duque pidió que «se le moderasen y quitasen tantas guardas como tiene» (p. 523). Por cierto, Quevedo también comenta ambos encarcelamientos en carta de 13 de junio de 1645, sorprendido por la falta de noticias al respecto: «Gran cosa es el silencio de la prisión del Protonotario y el de la prisión del duque de Medina Sidonia» (p. 180).

Teniendo en cuenta el creciente interés ${ }^{17}$ por la obra menor de Quevedo, que complementa la brillantez de otros de sus textos, pretendemos cotejar algunas opiniones del escritor en estos difíciles cinco años últimos de su vida, limitándonos a un corpus reducido, circunstancial y muy personal: desde el impacto que dejan en el preso de León las rebeliones de 1640, según los dos escritos compuestos al respecto en 1641; el Memorial que escribió don Francisco de Quevedo al Conde Duque, también de 1641; el Memorial de don Francisco de Quevedo suplicando su soltura de la prisión que padecía en san Marcos de León, dirigido al rey en 1643; y el Panegírico a la majestad del rey nuestro señor don Felipe $I V^{18}$, también de 1643, hasta sus patéticas cartas de 1645. A pesar de las diferencias genéricas, que son muchas, y considerando como «menor» ${ }^{19}$ no solo las obras breves, sino las coyunturales, los textos de nuestra selección coinciden en la relación “prisión-enfermedades»-que se aprecia en los dos memoriales y en muchas cartas-, y de ella deriva la escritura de tres opúsculos políticos bien distintos y cronológicamente consecutivos: la Respuesta al manifiesto..., La Rebelión de Barcelona... y el Panegírico... a Felipe IV. Los dos primeros son obras polémicas, o comentarios históricos y políticos que coinciden con la política del rey y

16. O de la que no nos ha llegado información, por la falta de avisos desde septiembre de 1642, según explican los editores de los Avisos, Chevalier y Clare, 2002, I, p. v.

17. Rey, 1993, ya reclamaba atención para estas obras.

18. Cito por la edición de Rey, 2005.

19. Ettinghausen, 1995, p. 254. 
su valido, y el tercero es una ceremoniosa y muy interesada alabanza de Felipe IV por haber despedido a Olivares. A falta de datos fechados con exactitud $^{20}$, podemos intuir que el preso de León empieza a organizar una estrategia de promoción personal hacia mediados de 1640, y que las rebeliones de Cataluña (junio de 1640) y Portugal (diciembre de 1640) le dieron ocasión para manifestarse como un patriota.

De ser así, el Quevedo encarcelado no sólo recordaría su actividad de propagandista ${ }^{21}$ contra el enemigo francés en 1635 , sino que recuperaría su habilidad de comentarista para descifrar y denigrar los manifiestos del enemigo interno, gestándose, primero, su escrito contra la revuelta portuguesa, y poco después contra la catalana. En ambos casos firma con seudónimo, pese a que el contenido de ambas obras no le hubiera perjudicado en caso de divulgarse ${ }^{22}$. Los dos opúsculos son comentarios de textos anteriores en un doble sentido: y es que el preso de León contesta a los respectivos «manifiestos» enemigos, pero no directamente, sino que lo hace cuando conoce la respuesta oficial a los mismos, a la que él se suma. En el caso de la Respuesta... después de la Sucesión de los reinos de Portugal y el Algarve, de José Pellicer y Tovar, y en el caso de La rebelión... después del Aristarco, de Francisco de Rioja.

Si intentamos interpretar los todavía oscuros motivos de la prisión de Quevedo y sus relaciones con el conde-duque, sorprenden estos dos escritos por la agilidad del escritor, supuestamente viejo y enfermo, que aborda dos temas gravísimos y de actualidad, en aquella prisión cuyos dos primeros años fueron «como fiera, cerrado, solo en un aposento, sin comercio humano", según la dedicatoria de La caída para levantarse ( $\mathrm{p}$. 126). Las diferencias genéricas entre estos dos opúsculos, los memoriales y las $\operatorname{cartas}^{23}$ no sólo indican cuestiones de estilo, sino elecciones muy conscientes. En 1641 Quevedo recupera su actividad literaria y política con una especie de borrador contra los portugueses, y luego parafrasea y «acompaña» al Aristarco anti-catalán, redactado por un escritor hechura de Olivares; son dos pasos previos al Memorial que escribió don Francisco de Quevedo al Conde-Duque. Desconocemos si Olivares pudo leer las dos obritas, que hubieran podido preparar su ánimo, pero Quevedo en el Memorial de 1641 se limita a solicitar clemencia por su edad y enfermedades, y apela a la compasión del valido. Estos argumentos se intensifican en 1643, cuando dirige otro memorial, esta vez a Felipe IV, al que también dedica el Panegírico... por las mismas fechas, pero sin la menor alusión a cuestiones personales. De manera que estas

20. Jauralde, 1982, pp. 164-165, señala que ya en 1640 escribiría la dedicatoria de la Vida y martirio del Padre Marcelo Mastrili.

21. Para este aspecto, ver Arredondo, 2011 a, capítulo III, donde abordo los escritos de Quevedo y otros polemistas sobre las rebeliones de Cataluña y Portugal, con amplia bibliografía.

22. Ver Arellano, 2001.

23. Para la distinción entre cartas (sean familiares o epístolas literarias) y memoriales (sean públicos o privados), ver la Introducción de Rey al volumen vi de las Obras completas, 2015, pp. XI-XVII. 
obras de León se redactan sucesivamente a partir de circunstancias graves, tanto para el autor como para el gobierno de la Monarquía, en una vinculación de lo personal y lo político que se aprecia hasta el fin de sus días, como muestra el epistolario.

La Respuesta al manifiesto del Duque de Berganza es la primera de esas dos obras, el primero de los «balbuceos» ${ }^{24}$ de Quevedo en León, y para fecharla puede fijarse como término ad quem el verano de 1641, cuando se descubrió en Lisboa una conjuración para acabar con Juan IV y reponer a la Virreina, Duquesa de Mantua. En dicha conjuración participó por el bando pro-español don Agustín Manuel de Vasconcelos, que fue ajusticiado en agosto de 1641, y es el autor del texto que combate Quevedo: Sucesión del señor rey don Filipe II en la corona de Portugal, de 1639. La Respuesta al manifiesto... es una paráfrasis -como lo será poco después La rebelión de Barcelona...- o comentario de este texto, interpretado erróneamente como el «alevoso manifiesto» que preparaba la traición del Duque de Berganza. Probablemente en los primeros meses de 1641 llegarían a León las alarmantes noticias de lo sucedido en diciembre en Lisboa; y también de la confusión que reinaba en Madrid, donde, por ejemplo, se tenía por leal y heroica la actitud del Conde de La Torre (al que ensalza Quevedo), cuando en realidad se sumó posteriormente al bando portugués. Por ello Quevedo no fue el único en equivocarse, porque las sospechas sobre don Agustín Manuel aparecían en uno de los primeros textos pro-felipistas compuestos en Madrid, y que también debió de llegar a León: la Sucesión de los reinos de Portugal y el Algarve, fechado en diciembre de 1640 por José Pellicer y Tovar; y este cronista consideraba en los preliminares de su obra que la Sucesión... de don Agustín era el «prólogo» de la rebelión bragancista.

Cuando Quevedo pergeñó la Respuesta... partiría, previsiblemente, de su sincera preocupación por la revuelta, del recuerdo del texto de Vasconcelos, que declara haber leído, y de la obrita de Pellicer, propagandista oficial. Con esos mimbres y una situación más cómoda que la del primer año de prisión, se dedica a descifrar lo que ocultaba la Sucesión... de Vasconcelos. Porque para Quevedo la finalidad de aquel texto era defender el derecho del duque de Berganza al reino de Portugal (p. 393); de ahí que lo califique de «alevoso manifiesto», adelantándose a los que posteriormente justificaron la actuación de los rebeldes. Por eso Quevedo refuta fragmentos del autor portugués, defiende los derechos de Felipe II y sus sucesores y, ante la confrontación bélica, pinta la magnanimidad de Felipe IV como antítesis del «tirano» Berganza, en la Conclusión de su escrito:

Todo esto dispone que el rey, nuestro señor, que con Portugal ha juntado al título de señor obras de padre, tenga en aquel reino pocos quejosos, porque los muchos son los opresos, que darán paso al sentir de sus corazones

24. Jauralde, 1982, p. 164. 
cuando las armas justificadas les abrieren lugar para que respiren (p. 429).

La Respuesta... no pasa de ser un borrador, un mero ejercicio retórico sin pulir ${ }^{25}$. Don Francisco parece darlo por terminado con la colocación del seudónimo al final, pero luego añade una cita y un apólogo procedente del Libro de los jueces, como argumento para descalificar la elección de Berganza. A diferencia de La rebelión de Barcelona..., clara defensa de la política de Olivares, la Respuesta... refuta la Sucesión de don Agustín Manuel, que era, eso sí, uno de los portugueses afectos al valido. A este primer detalle ha de unirse el ataque de Quevedo a los judíos portugueses protegidos por el conde-duque ${ }^{26}$; pero es que también la Sucesión... de Pellicer ${ }^{27}$, intensificaba en su segunda edición las insinuaciones contra los mercaderes y asentistas portugueses, que compartiría Quevedo.

En una de sus primeras actuaciones el preso de León se aplica, pues, a descifrar un libro que, además, estaba dedicado al valido, con palabras lisonjeras para el rey y su ministro. Como si retrocediera en el tiempo, Quevedo escribe que la obra de Vasconcelos se le antojó sospechosa desde que la leyó en 1639: “Cuando leí esto al estrenarse el libro...» (p. 400). Y, en efecto, se dedica a rebatir el libro del portugués dedicado al conde-duque, que sólo aparece en dos ocasiones en la Respuesta... de Quevedo.

Primero aparece en la dedicatoria del libro de don Agustín, cuya portada transcribe minuciosamente Quevedo en su comentario:

Sucesión del señor rey don Filipe II en la corona de Portugal, en Madrid, con privilegio de Pedro Tazo, año 1639. Aprobado por el ordinario, por el doctor Agustín Barbosa, protonotario y juez apostólico en la Corte, y, por el Consejo, por el maestro Gil González de Ávila, coronista de Su Majestad en los reinos de Castilla. Dirigido al excelentísimo señor Conde-Duque.

Sin embargo, desde la edición de Fernández Guerra se ha interpretado erróneamente el «Dirigido al excelentísimo señor Conde-Duque», creyendo que era Quevedo quien dedicaba obsequiosamente su comentario al valido que lo había encarcelado.

$\mathrm{Y}$, en segundo lugar, Olivares aparece brevemente en una sola línea relativa a la generosidad para con los portugueses «de su majestad y su valido» (p. 419). Todo ello hace pensar que nos hallamos ante una obra menor, un desahogo del patriótico Quevedo encarcelado, y un juego literario o reprimenda contra los que aprobaron el libro -siendo «libro de portugués» y «un año después del levantamiento de Évora» (p.

25. Como ya he señalado en la edición del texto, p. 430, nota 184.

26. Ya lo señaló Ettinghausen, 1995, p. 251.

27. A este respecto, para las malas consecuencias de dichas insinuaciones, ver Arredondo, 2016. 
395) - y permitieron su publicación: el protonotario apostólico Barbosa y el cronista González Dávila.

A continuación de este intento Quevedo compuso La rebelión de Barcelona, un panfleto satírico más logrado, en donde comenta y ataca el manifiesto dirigido por las autoridades catalanas a Felipe IV: la Proclamación católica (1640). La obra puede fecharse en el segundo semestre de 1641, porque Quevedo combate los argumentos de la Proclamación parafraseando el Aristarco, la respuesta oficial que apareció en julio de 1641, según un aviso de Pellicer. La Rebelión de Barcelona es un texto cerrado, donde el autor, ya más seguro, declara que escribe «Habiendo visto el Aristarco o Censura a la que llaman los catalanes Proclamación católica) (p. 447), y que lo hace «no por crecerle ni añadirle, sino por acompañarle» (p. 448).

En efecto, a diferencia de la Respuesta, donde Quevedo hubo de remontarse al texto de 1639 sobre la sucesión de Felipe II, y donde no cita nunca la obrita de Pellicer, la Rebelión de Barcelona parte del Aristarco, porque probablemente no pudo leer la Proclamación católica que fue rápidamente recogida por la Inquisición. Esta diferencia es fundamental, porque el Quevedo encarcelado pisa ahora terreno firme, aunque seguramente sus opiniones contra el escrito emanado de la Generalitat fueran sinceras. La declaración citada explica por qué estructura Quevedo su Rebelión en función del refrán: en una captatio benevolentiae el satírico de León afirma que va a rebajar el tono, y que escribirá «lo que despreció la severidad de aquella pluma» -la de Rioja- para que los catalanes «si no obedecieren al docto, padezcan al ignorante» (p. 448). Por eso la obrita de Quevedo comparte los puntos de vista oficiales expuestos por Rioja en su refutación de la Proclamación, y añade, si no argumentos, sí aspectos eruditos y satíricos con un brillante estilo. De todo ello lo más significativo es que nuestro autor no se limita a exaltar al rey (como padre de los catalanes) y apoyar la política del conde-duque, de la que se quejaba el texto catalán, sino que exagera la defensa realizada por el Aristarco. Frases como «Exprimido todo el veneno que en la Proclamación confeccionaron los sátrapas de Cataluña, se encamina por ellos al conde-duque» (p. 462), “Toleró en Barcelona el conde-duque el demasiado orgullo de los catalanes. ¿Qué no hizo por disponer su desorden?» (p. 463), o “Ven que el conde-duque, por su integridad, desinterés y asistencia inimitable tiene el primer lugar» (p. 466) indican, o una extremada identificación con la figura del valido y su política, o un hipócrita fingimiento para adherirse a la propaganda oficial.

Las dos obritas se escriben en el mismo año que el primer Memorial que dirige Quevedo a Olivares, al que halaga descaradamente, tanto como lisonjea a Felipe IV en el Panegírico de 1643. Pero a la hora de juzgar las ideas políticas de Quevedo, estas dos obras de circunstancias -y nunca mejor aplicado el término- nos muestran a un escritor que recupera poco a poco su tarea literaria y que intenta mejorar su delicada situación. De ahí la dificultad para extraer conclusiones sobre la sinceri- 
dad de sus opiniones, y para establecer una coherencia ideológica entre el preso y el escritor.

Tras estas dos obras exclusivamente políticas, Quevedo escribe un Memorial a Olivares en 1641, absolutamente personal y privado, donde los detalles de su detención y las acusaciones vagas a los «enemigos» y la «envidia» se mezclan con la vejez («sesenta y un años») y las enfermedades (“enfermo por tres heridas que, [...] se me han cancerado» (p. 389). Vejez y enfermedades también aparecen en el Memorial a Felipe IV, de 1643, y en dos cartas de ese año. Por ejemplo, en abril de 1643 informa al padre Juan Antonio Velázquez de que «Dios nuestro Señor ha mandado que la enfermedad me ponga grillos a los pies» (p. 125), y se refiere a que lleva dos meses «tullido» (29 de abril 1643, p. 126), sin poder gozar de los rumores que anuncian su pronta liberación (p. 125). Pero también el 29 de abril Quevedo parece trazar una estrategia para emplear la edad y las enfermedades como argumento compasivo ante quien le «favorece», don Juan Chumacero: «Mucho importa que Vuestra Reverendísima le hable representándole mis trabajos» (p. 126).

En septiembre de 1643 la primera carta a Sandoval tras salir de prisión informa de que «ahora aprendo a andar», y los dolores se incrementan en los años sucesivos: en carta a Sandoval de 11 de febrero de 1645 dice que está sitiado de (achaques desapacibles» (p. 168), y en carta a Francisco de Oviedo de 21 de febrero de 1645 que está «rendido del dolor» (p. 170). Sin embargo, pese a las dolencias, su pasión por la política se manifiesta continuamente en el epistolario, desde 1642 hasta el socorro de Rosas en 1645. Las cartas de 1642 al padre Pimentel contienen mucha información procedente de noticias que recibe Quevedo de Madrid; por ejemplo, cuando en septiembre deja entrever su cuidado sobre el frente de Aragón, incluyendo una expresión utilizada en $\mathrm{La}$ Rebelión de Barcelona: «temo mucho tan larga asistencia de castellanos en Aragón, que en fin el contagio de Cataluña es pariente, y en tierra donde los disgustos no son por el huevo, sino por el fuero las sospechas suelen ser por el uno y por el otro» (p. 84).

Algunas cartas de estos años, las menos, son amistosas y de menor enjundia, como las dirigidas a Sandoval, agradeciendo obsequios y contando chismes y pequeñeces domésticas; o la de abril de 1643, al padre Velázquez, refiriéndose con cierta guasa a los libros y el chocolate que manda desde América el obispo Palafox: «el mar y las borrascas tienen más golosina del chocolate que envía el señor Palafox, pues se le traga, que de sus libros, pues los envía» (p. 126). Y parece que a partir de mayo Quevedo habla confiado en su pronta liberación: se muestra ya como informante, tildándose de "gacetero» en octubre de 1643 (p. 135). A este respecto no deja de sorprender la seguridad con que se expresa este Quevedo, viejo y alejado del poder, en sus informaciones políticas, por ejemplo, sobre Haro y Olivares, en carta a Sandoval de 2412-1644 (pp. 160-161). No obstante, la prisión ha dejado tal huella que, transcurrido un año de su liberación, en agosto 1644 vuelve a contar 
los detalles en la dedicatoria a Chumacero de la Vida de San Pablo ${ }^{28}$, y en noviembre de 1644 relaciona su prisión y enfermedades con una insinuación sobre su, o sus, responsables: «cuatro años de prisión estudiada por el odio y la venganza del poder sumo» (carta a Sandoval, p. 151).

A diferencia de esas variadas informaciones que transmite Quevedo a los amigos, vejez y achaques aparecen en los memoriales de 1641 y 1643 casi exclusiva e interesadamente, para relacionar la violenta detención, la cárcel rigurosa y la responsabilidad de quien o quienes la decretaron.

El primero de los memoriales está dirigido a Olivares y fechado en León, el 7 de octubre de 1641. Es un texto breve y bien estructurado, que pretende conmover, que reconoce ambigua y difusamente algún tipo de error o culpa («Yo propio soy voz de mi conciencia y acuso mi vida», p. 389), y que demuestra convicción en la clemencia y en el poder del destinatario ${ }^{29}$ para mejorar las condiciones del preso. Es un escrito que distribuye muy bien el contenido. Ya en el segundo párrafo se marca la duración de su rigurosa prisión (“un año y diez meses»), con detalles de su enfermedad, su vejez (sesenta y un años), pobreza, y soledad (sólo una hermana, que no puede socorrerle); para solicitar a continuación la piedad («Cuando yo sea indigno de piedad vuestra excelencia es dignísimo de tenerla, propia virtud de tan gran señor y ministro» p. 389), afirmando: “Todo lo he perdido» (p. 390).

Es muy notable en el texto la antítesis patética «Ninguna clemencia puede darme muchos años, ni quitarme muchos años algún rigor», porque Quevedo pide, no «por vivir más», sino «por vivir bien algo, aunque poco» (p. 390); y que ese tiempo redunde en la gloria de quien se apiada de él: «Para que yo sea no pequeña porción de gloria al nombre de vuestra excelencia». Como bien dijo Crosby, «perdonar a Quevedo tendrá el resultado de engrandecer al Conde-Duque» ${ }^{30}$.

Y es reveladora la doble comparación del monarca y su valido con Trajano y Plinio Segundo, a los que presenta Quevedo, respectivamente, como los antecesores en la excelencia de sus funciones. Ello indica que en 1641 Quevedo percibía la identificación de los dos pilares de la Monarquía: «Los tiempos, no los méritos, adelantaron este emperador y este valido a tan glorioso monarca en su majestad, a privado tan desinteresadamente celoso como vuestra excelencia» (p. 392). Y que pensaba en Olivares como el mediador adecuado para su liberación: «La autoridad de vuestra excelencia ha de interceder con su majestad, y su propia grandeza consigo» (p. 390). En suma, este memorial es un texto muy cuidado, lisonjero, rebuscado en sus conceptos, pero sin da-

28. «Fui preso con tan grande rigor, a las once de la noche, siete de diciembre, y llevado con tal desabrigo, en mi edad» (La caída, p.126)

29. Rey, 2015, p. xL, afirma que al dirigirse a Olivares Quevedo «considera que ha tenido alguna participación en su detención y consecuentemente, que puede contribuir a devolverle la libertad».

30. Crosby, en Quevedo, Nuevas cartas, p. 194. 
tos precisos ${ }^{31}$. El autor no habla ni de sus «papeles» ni de los servicios prestados, como hará dos años después.

El segundo memorial lo dedica al rey. No lleva fecha, pero un valioso dato temporal, tres años y tres meses de prisión, permite fecharlo en marzo o abril de 1643; por ello debe relacionarse con las dos cartas citadas dirigidas al padre Velázquez para encarecer los rigores de la prisión, cuyo resultado serán las palabras de Chumacero en las consultas al rey.

En el primer párrafo del Memorial de don Francisco de Quevedo suplicando su soltura de la prisión destaca un cambio político fundamental para la Monarquía y para él mismo: cya que vuestra majestad es ministro de sí mismo», igual que en el Panegírico a la majestad del rey nuestro señor don Felipe IV («damos parabienes a la Monarquía de que vuestra majestad es ministro de sí mismo», p. 490), compuesto por las mismas fechas. Por ello Quevedo expone ahora, y al rey, su doble agravio: que le quitaran los «papeles» $\mathrm{y}$ en todo ese tiempo no se hayan visto, $\mathrm{y}$ "haberle preso y destruido en honra, vida y hacienda» (p. 399).

Este memorial es un escrito escueto y bien organizado, con exposición, argumentación y súplica. La argumentación se basa en que el rey no tenía información suficiente y verdadera sobre el caso de Quevedo, porque «los ministros por quien ha corrido [su agravio] siempre dijeron otra causa [...] sin nombrar sus papeles»; papeles de los que el autor parece estar orgulloso, porque siempre han sido «del servicio de Dios y de la Iglesia y de vuestra majestad y de su monarquía contra los enemigos de ella» (p. 399). El plural «ministros» no oculta que el preso de León se refiere a uno solo, el destituido recientemente. Y precisamente ahora Quevedo pone en consideración del monarca que el agravio contra él se repite, porque ya ha estado preso otras veces, sin que se le hiciera cargo ni tomara declaración, y luego fue puesto en libertad, sumando todo cinco años que le han perjudicado en su «hacienda» y en «la salud con rigores terribles» (p. 400).

El tono del escrito es seco y duro: el rey «no ha tenido noticia [...] Hoy la tiene». Por ello no pide "satisfacción», sino que no le acabe «el odio y la pasión no ocasionada por él»; y que el rey ataje estos males, porque eso es lo que corresponde: «lo que debe a su real persona» (p. 400). Quevedo da a entender que el rey no estaba al corriente cuando lo apresaron, pero ahora puede y debe tomar decisiones para corregir la doble injusticia. El contraste entre un antes (con ministros interpuestos) y un hoy (ministro de sí mismo) parece bastar para la petición, junto con el recordatorio de sus anteriores prisiones: dos por el caso Osuna y una por el patronato de Santiago, causas de las que no parece avergonzarse el autor.

El texto no lleva citas ni ornato retórico, sino que en él prevalece el estilo formulario de un escrito oficial que, efectivamente, llegó a manos del Consejo y posteriormente del rey. No obstante, la mención de la sa-

31. Rey, 2015, p. xL, opina que es un escrito «cauteloso»y de «tanteo». 
lud y la destrucción de honra, vida y hacienda son los pilares para la súplica. De hecho, la cuestión de la edad y el deterioro de la salud del preso se exageró por parte del presidente del Consejo, Juan de Chumacero, en sus dos consultas al rey. Primero, el 3 de mayo de 1643, informa de que «Su edad es mucha, y los achaques tan continuos [...] que no se levanta de la cama; y hoy dicen está enfermo de peligro». Y el 7 de junio insiste en que atiene muy cerca de setenta de edad y tan lleno de achaques que no se levanta de la cama, y se duda de su vida» (p. 402).

Sin embargo, en el Panegírico, del que sólo sabemos que fue redactado después de enero de 1643, previsiblemente con poca diferencia de tiempo respecto al Memorial... dirigido al rey, Quevedo no incluye ni una palabra sobre sí mismo. Como corresponde a otro género literario, el Panegírico a la majestad del rey nuestro señor don Felipe IV es un texto muy elaborado, que se apoya y adorna con citas, unas bíblicas y otras clásicas, como por ejemplo la de Silio Itálico, también presente en la Carta a Luis XIII. El estilo elevado de la obra, que es una alabanza hiperbólica del rey, se apoya en muchas metáforas y se basa en la comparación del rey Felipe IV con Cristo: «Considero en vuestra majestad esta imitación de la persona de Cristo» (p. 487), así como en una antítesis reiterada: gobernando con el valido se producía temor y separación en sus vasallos; y en cambio el gobierno personal del rey -«desde el día en que hablasteis en el Consejo de Estado», tras la destitución de Olivares- obró una «maravilla tan grande» que el escritor la expresa en una sucesión de infinitivos a cual más halagüeño: «alegrar la tristeza, confiar la desesperación, alentar el desmayo, enamorar el miedo, enriquecer la pobreza, desaprender la mentira, arrepentir los rebeldes y atemorizar los enemigos» (p. 487).

En el texto aparecen palabras clave, como «gloria», también presentes en las cartas de la misma época y sobre el mismo tema, como la dirigida al padre Velázquez, en febrero 1643: «Aseguro a Vuestra Reverendísima [...] que si pudiera apartar de esta novedad la gloria que de ella resulta a su Majestad» (p. 119). Y como «hoy», cuando Quevedo augura un futuro espléndido para los españoles a partir de ese «hoy», un presente prometedor, porque recuperarán lo mejor de su pasado y volverán a su «valor solariego» (p. 491), con el que realizaron grandes hazañas. Ese «hoy» contrasta con el pasado reciente, porque los españoles «con vuestra ausencia han parecido otros, por desdicha, no por culpa» (p. 492), mientras que «hoy» se abre camino hacia el futuro. Así que la antítesis "presencia del rey / ausencia del rey» indica que Felipe IV recuperará el amor de sus súbditos, tras veintidós años de «temor inducido y forzado» (p. 484), y que volverá la lealtad a esos españoles ${ }^{32}$

32. Los españoles son siempre leales, según La rebelión: «al español más le constituye el serlo la lealtad que la patria» (p. 451). Respecto a que «han parecido otros», Rey interpreta como «han aparecido» (p. 492, n. 67), mientras que si lo entendemos como "parecerse una cosa a otra: semejarse», s.v. (parecer», en el Tesoro de Covarrubias, podemos 
en tiempos de rebeliones internas y guerras externas, desquitándose de las «calamidades que han padecido».

El Panegírico al rey sirve para denostar, aunque muy soterradamente, a los «ministros de impedimento» (p. 484), es decir, a quien Felipe IV elevó de «vasallo» a «compañero de las resoluciones del gobierno» (p. 486); y a pesar de que Quevedo justifica prudentemente la elección del entonces joven rey:

Para que convenga que sólo merecéis ser tan grande rey que lo seáis solo, no es menester que los que os han asistido sean defectuosos; basta, señor, sin su descrédito, que no sean capaces del talento real del espíritu soberano (p. 485).

La cautela del escritor, que elogia repetidamente la decisión del rey, se percibe incluso cuando habla de «culpa» dos veces, al final del Panegírico; primero, con una alusión clara al valido: «La culpa tiene quien a vuestra majestad le desconfió de todos»; y segundo, cuando se designe suavemente al mismo, por medio del plural: «El apartar semejantes personas no presupone culpa suya, siempre suele ser conveniencia forzosa» (p. 494).

Por otra parte, la escritura del Panegírico parece indicar una visión política esperanzada, como indica la insistencia en la madurez del rey, que tenía treinta y ocho años en 1643, frente al comienzo de su reinado, cuando su juventud necesitó la ayuda del conde-duque. Esto puede deberse a la nueva imagen que deseaba exaltar Quevedo. Felipe IV era un rey-soldado, en la Carta a Luis $\mathrm{XIII}^{33}$; un rey con gran poder, comparado con Julio César al final de La Rebelión de Barcelona, contra el que atentan en vano el rebelde Berganza y los catalanes ${ }^{34}$; y ahora un rey maduro y omnipresente, en el despacho y en la batalla: «Señor, si los soldados de vuestra majestad ven vuestras espaldas, ellos harán que veáis las de los enemigos» (p. 491), como en Política de Dios ${ }^{35}$ y en Suspiros de Francia, de Saavedra Fajardo. En esta obra, también de 1643, se usa como argumento el gobierno en solitario de Felipe IV -«Y si se confirma por diferentes avisos ha tomado el Rey de España sobre sí todo el peso de la Monarquía, sin fiar de los ministros» ${ }^{36}-$, frente a un

interpretar que los españoles habían perdido su esencia «leal», que ahora recuperan y se parecen a ellos mismos.

33. «Hoy el rey mi señor, provocado de vuestras armas, os buscará, pues así lo queréis, no con nombre de enemigo. Su apellido será católico, vengador de las injurias de Dios» (citamos la Carta por la edición de Peraita, 2005, p. 287.

34. “Persuadirse él con los catalanes y ellos con él que su traición debilita el gran poder del monarca de España es locura» (Rebelión, p. 469)

35. «Rey que pelea y trabaja delante de los suyos, oblígalos a ser valientes; el que los ve pelear los multiplica, y de uno hace dos» (Citamos Política, por la edición de Crosby, p. 62).

36. Citamos Suspiros de Francia por la edición de Rosa de Gea, 2008, p. 388. 
Luis XIII enfermo (murió en mayo 1643): «saliendo a campaña aquel Rey, mozo de buena salud, y asegurada la sucesión» (Suspiros, p. 389).

Esas expectativas optimistas sobre la nueva forma de gobierno y las ventajas que a Quevedo podría acarrearle condicionan el estilo del Panegírico, que puede indicar la actitud teórica y reflexiva de quien está alejado del poder ${ }^{37}$. Por ello el estilo es propio de un texto no sólo lisonjero, sino muy cuidado y de gran valor emblemático. Por ejemplo, la metáfora del sol y su sombra coincide con una imagen de las Empresas de Saavedra Fajardo, donde el valido tiene solo luz "prestada»: "Obre el valido como sombra, no como cuerpo» ${ }^{38}$, “obre con más autoridad que todos el valido, que es sombra del príncipe» (p. 583). El campo semántico elegido por Quevedo para el Panegírico es grandioso, partiendo de las diferencias entre el sol, que es el rey, y las nubes o los eclipses que lo ocultan:

Acabasteis los años que vuestra luz nos la dispensaron pálida vapores que levantasteis y condensaron nubes, por cuyos ceños el día que nos enviábades como sol clarísimo descendía a nuestros ojos anochecido en los tránsitos que le esquivaron con sombras (p. 483).

A propósito de esa confianza en el futuro, y aunque pueda dudarse de la sinceridad de los elogios, Quevedo expresa en las cartas una opinión favorable al gobierno en solitario del rey. Por ejemplo, en marzo de 1643, cuando cita las palabras de Felipe IV: “Quiero descoser y no desgarrar"; y parece que así lo hace con gran prudencia y menos ruido" » (pp. 124-125); y el respeto por Felipe IV parece no resquebrajarse ni siquiera por la frase dilatoria con que respondió a Chumacero en 1643 («la prisión de don Francisco fue por causa grave»), porque en diciembre de 1644 informa positivamente: «Su Majestad despacha por sí solo» (p. 161).

En cuanto a opiniones estrictamente políticas, además de los halagos del Panegírico, y de las declaraciones patrióticas sobre las rebeliones catalana y portuguesa, resulta desconcertante cómo enjuicia Quevedo al conde-duque en el Memorial dirigido a Felipe IV en 1643. Habida cuenta de las diferencias estructurales y estilísticas que existen entre los dos memoriales, quizá convenga tener en cuenta una segunda versión de este último, supuestamente apócrifa, pero que edita Alfonso Rey en Apéndice por su gran interés. En este texto el tono es aún más duro que en el Memorial de don Francisco [...] suplicando su soltura de la prisión, porque el suplicante afirma que ha pedido varias veces que se le oiga, infructuosamente. De ahí que insista en la palabra (justicia», en las «dolorosas circunstancias de su prisión» (p. 403); y que esa palabra

37. Así opina Grilli, 2014, que ha señalado la actitud de este Quevedo "politólogo» (p. 83).

38. Cito por la edición López Poza, 1999, empresa 49, p. 586. Ver también Benigno, 1992. 
"prisión» sea objeto de una amplificación: «contra todo derecho», junto a términos y conceptos que ya aparecían en otros escritos: «en agravio de su persona, reputación, vida y hacienda».

De la misma manera, si nos preguntamos una vez más sobre las relaciones entre Quevedo y Olivares, y sobre las causas de la detención, podríamos tener en cuenta el memorial Si no es la esperanza, dedicado al conde-duque y en el que se pide que le mudara de prisión. El texto fue descubierto y analizado por Isabel Pérez Cuenca y Manuel Urín ${ }^{\prime 39}$ y editado como apócrifo por Crosby en 2005. De ser admitido entre las obras de Quevedo, permitiría verificar una secuencia temporal entre el primer memorial a Olivares de 1641, que recordaba al final que el preso «espera nueva vida» (p. 392), y este segundo, con la frase "pido mudanza de lugar» (p. 428), y así explicar las mejores condiciones en la prisión de León.

En suma, hay todavía muchos aspectos oscuros relativos al último periodo de la vida de Quevedo que pudieron causar notables oscilaciones en sus opiniones políticas. Por ejemplo, en carta de 1645 a Francisco de Oviedo dice: «Señor don Francisco, en tanto que en Cataluña quedare algún solo catalán, y piedra en los campos desiertos, hemos de tener enemigos y guerra» (p. 169). Este tono coincide con las diatribas expresadas en 1641 en La Rebelión: «Esta gente de natural tan contagioso, esta provincia apestada con esta gente, este laberinto de privilegios» (p. 465); pero no con lo que afirma en 1643 en el Panegírico: «Nunca, señor, nunca los catalanes aborrecieron vuestro justificado señorío, sino los medios que los desesperaban de él: si éstos pudieron desviarlos de vuestra majestad, vos podréis reducirlos» (p. 494).

En cualquier caso no hay duda de la satisfacción y confianza en la decisión del rey sobre la salida de Olivares, que celebra Quevedo con cierta ironía (tropezón, desliz, tan gran ministro) en carta de febrero de 1643:

Aseguro a Vuestra reverendísima, en Dios y en mi conciencia que si pudiera apartar de esta novedad la gloria que de ella resulta a su Majestad [...] y las mejoras del bien público, que sintiera el tropezón sea desliz de tan gran ministro. Mas como el Rey nuestro señor nos ha trocado el siglo de hierro en buena moneda y con tan esclarecida liberalidad nos hace vivir años de oro es deuda mostrar regocijo (p. 119).

En esta misma carta bienhumorada se declara viejo («estoy de la otra parte de decrépito», p. 119), y como «el contar cuentos es la tarabilla de los viejosm, Quevedo cuenta el suyo para apoyar el gobierno sin valido, con el ejemplo de los Reyes Católicos: «que la Reina era el privado del Rey, y el Rey el privado de la Reina, y que con esto decía que no podían ir mejors (p. 119).

39. Pérez Cuenca y Urí, 2001. 
En realidad Quevedo sólo se atreve a manifestarse contra Olivares en escritos privados, concretamente en algunas cartas; y recordemos que Olivares fue destituido en enero de 1643, llegó a Toro en junio y murió en julio de 1645, mes y medio antes que el escritor. Pues bien, todas las noticias referentes a la salida de Olivares se recogen en las cartas de enero y febrero de 1643, y el paralelismo de ambos destinos se recalca por dos veces en la correspondencia. Primero, a propósito de la llegada de Quevedo a la corte: «yo entré de allende los puertos el día que salió el que me arrojó de este lugar» (p. 134). Y después, con arreglo a la costumbre de fechar según el santoral, Quevedo sitúa la muerte del valido el día de la Magdalena («Bien memorable día debe de ser el de la Magdalena, en que acabaron con la vida del conde de Olivares tantas amenazas y venganzas y odios que se prometían eternidad»), dos meses después de la suya propia, el 25 de abril, día de San Marcos, cuando recibió el viático y comenzó su mejoría o «resurrección»: «Yo he estado en manos de Nuestro Señors (p. 176), dice el 14 de mayo a Francisco de Oviedo. Sin embargo, un enfoque tan piadoso no oculta una conclusión rencorosa o vengativa: «Yo, que estuve muerto día de San Marcos, viví para ver el fin de un hombre que decía había de ver el mío en cadenas» (p. 184).

Salvo estos comentarios y el que desliza en octubre de 1643 sobre Olivares y el poder absoluto - «Tengo por rígido noviciado el desaprender el poder absoluto entre esperanzas y sospechas» (p. 135)Quevedo se refiere al valido con precaución en estos años; por ejemplo con el anagrama “Magaraz» (don Gaspar de Guzmán), desde 10 de febrero de 1643 (p. 121), frente al juguetón "Asperilla», en la carta a Sandoval de 12 de febrero de 1635: "y yendo Su Majestad, si fuere, habrá menos Asperilla y más don Felipe» ${ }^{40}$.

Las opiniones a favor son siempre interesadas y coyunturales, como cuando Quevedo afirma que el conde-duque es «recto y bueno» (p. 463) en la Rebelión de Barcelona, donde no sólo refutaba las quejas contra Olivares de la Proclamación Católica, sino que elogiaba al «doctísimo" Aristarco, de Francisco de Rioja. Pero del mismo Rioja escribió Quevedo después, a propósito del escrito de Andrés de Mena contra el conde-duque y de la respuesta exculpatoria en la que Rioja colaboró. Y entonces, cuando ya había caído el valido y Quevedo estaba a punto de ser excarcelado, dice con poco respeto que «Rioja se juzga inundado de todas las ciencias» (carta de junio de 1643, p. 129). De manera que sólo en dos textos de 1641, La Rebelión y el Memorial, Quevedo lisonjea al poderoso ministro del que se había alejado en los últimos años ${ }^{41}$,

40. Citamos esta carta por la edición de Sánchez, 2009, p. 238.

41. A este respecto, Nider, 2004, p. 198, ha señalado que el escritor siempre reconoció en Olivares «cierta grandeza». Y también Pérez Cuenca y De la Campa, 2012, p. 123, afirman a la luz de varias obras del autor que «tal vez no sea Quevedo quien se aleja del programa político e ideológico de Olivares [...] sino el privado el que toma distancia respecto al escritor». Ver también Rey, 2010. 
porque apenas habla de Olivares en la Respuesta al manifiesto, salvo en la Conclusión, cuando Quevedo afirma que el rey y el valido compartían la benevolencia para con la Casa de Berganza.

En fin, un Quevedo viejo y aislado, cuyo mundo se ha ido reduciendo, pasa de expresar su parecer sobre la política internacional ${ }^{42}$, a considerar los problemas internos con catalanes y portugueses, y desciende en sus cartas hasta los asuntos domésticos. Estos son testimonio de un Quevedo nada cortesano que padece la soledad, la enfermedad y las mermas de su hacienda, incluso porque le roban sus criados, según cartas de 1644, a Sandoval, «un criado que tenía aquí más habrá de catorce años, me robó todo cuanto tenía» (p. 154), y de 1645, a Oviedo: «Tras todos mis trabajos, un criado mío [...], gallego de nación, viéndome en el estado miserable de mi salud, me robó cuanto tenía» (p. 177). Así hasta reducirse a la consideración dolorosa de su propio cuerpo, «Este miserable cuerpo» (p. 161), en carta a Oviedo de 1645. Sin embargo, su interés por la política permanece, como cuando incluye un comentario irónico, en vista de su mala salud, a propósito de en qué manos quedará el gobierno: «Nadie escribe de quiénes quedará el gobierno en ausencia de su Majestad y del príncipe nuestro señor (mire v. m. qué cuidados me matan a mí entre mis achaques, sin irme ni venirme» (p. 166).

Antes de llegar al patetismo de quien ya intuye la muerte, el autor achacoso expresaba sus deseos de trabajar en el Marco Bruto y las “obras de verso» (enero de 1645, p. 165), y recordaba con amargura el escaso reconocimiento del Duque del Infantado ${ }^{43}$, al que había dedicado la obra en 1644. Como si creciera su lucidez tras la «resurrección» de su grave enfermedad, Quevedo afina su ironía referida al Duque: «que aún no me dijo que Dios me diese salud, ni que le había leído. Yo quiero al Duque bien de balde y le deseo todo gusto que su grandeza merece» (Carta a Oviedo, junio 1645, p. 180).

$\mathrm{Y}$, aunque en diciembre de 1644 Quevedo escribía que «Sólo vivo para verme muerto» (p. 157), hay cartas de 1645 que indican su mejoría (o resurrección), y vuelve a comentar noticias de guerra y política en cuatro cartas a Oviedo y en la penúltima a Sandoval (p. 182).

Efectivamente, a pesar de sus dolencias, Quevedo tiene buena memoria, y las experiencias del pasado dejan huella en estas cartas. Se comprueba por su insistencia en las noticias sobre la pérdida de Rosas, que él asocia con la enemistad que sentía el Cardenal Borja por el Duque de Osuna ${ }^{44}$. Así, en cartas del 13 y 20 de junio de 1645, Quevedo menciona el fracaso de la armada capitaneada por don Melchor Francisco Antonio de Borja. Como en ambos casos habla del «socorro» y la «pérdida» de Rosas, achacándolo a don Melchor, parece que el viejo Quevedo se

42. Ver Martínez Millán, 2014, p. 103, donde afirma que Quevedo percibió con nitidez la decadencia, y que las contradicciones de sus escritos son fruto del contraste entre los ideales políticos de una Monarchia Universalis y los de la Monarquía Católica.

43. Para las relaciones entre ambos, ver Crosby, en Quevedo, Nuevas cartas, pp. 63-64.

44. Ya he señalado este aspecto en Arredondo, 2011b. 
repite. Pero en la segunda carta añade el parentesco del marino, que era hermano del Cardenal, y saca conclusiones relativas a la enemistad entre don Melchor y el Virrey Osuna, que hasta entonces había callado o encubierto. En la primera carta Quevedo declara que siempre tuvo “pocas esperanzas» en el socorro de Rosas, y establecía una relación de causa-efecto entre la pérdida y el marino: «No debe de haber podido más, pues no ha hecho nada». Pero el juicio empeora todavía en la carta siguiente, cuando recuerda que en 1611-1612 gobernaba la escuadra en Sicilia don Melchor, «a quien se la quitó» el Virrey para entregársela «a don Octavio de Aragón, a quien el Rey nuestro Señor confirmó el título de capitán general [...], por razones que el Duque de Osuna dio a Su Majestad» Y añade: “esta fue la primera causa por la cual el señor cardenal Borja persiguió hasta la muerte al duque, mi señor» (p. 181).

Para concluir, según vemos en estas cartas, el último año del viejo Quevedo, pendiente siempre de la actualidad política, está marcado por los recuerdos y por noticias de guerras y enfermedades, ya que «Los sucesos de la guerra me parecen a los de mi convalecencia: salgo de un mal y entro en otro» (p. 183).

Así se expresaba ingeniosamente todavía en julio de 1645. Sin embargo, tres días antes de su muerte, Quevedo anunciaba a Oviedo con un tono tan lúcido como desgarrador- que le ha llegado el final: «Perdóneme v. m. que no discurra en cosas de la guerra ni de las paces, que pareciera ociosidad, ajeno del peligro en que me hallo» (5-9-1645, p. 190).

\section{Bibliografía}

Arellano, Ignacio, «La transmisión de la obra de Quevedo», Anthropos, 6, 2001, pp. 34-37.

Arredondo, M. ${ }^{\mathrm{a}}$ Soledad, Literatura y propaganda en tiempo de Quevedo. Guerras y plumas contra Francia, Cataluña y Portugal, Madrid, Iberoamericana / Vervuert, 2011a.

Arredondo, M. ${ }^{\mathrm{a}}$ Soledad, «El Virrey Osuna y sus imágenes literarias. Política y guerra, de la realidad a la ficción», en Cultura della guerra e arti della pace. Il III Duca di Osuna in Sicilia e a Napoli (1611-1620), ed. Encarnación Sánchez García, Napoli, Tulio Pironti, 2011b, pp. 479-493.

Arredondo, M. ${ }^{a}$ Soledad, «José Pellicer ¿́cronista marginado? El Comercio impedido por los enemigos desta Monarquía», en Heterodoxia, marginalidad y maravilla en los Siglos de Oro, dir. José María Díez Borque, ed. Jaime Olmedo y Laura Puerto, Madrid, Visor, 2016, pp. 11-26.

Benigno, Francesco, La sombra del rey: validos y lucha política en la España del siglo XVII, Madrid, Alianza, 1992.

Crosby, James O., «La última prisión de Quevedo. Documentos atribuidos, atribuibles y apócrifos», La Perinola, 1, 1997, pp. 101-122.

Elliott, John H. «Nueva luz sobre la prisión de Quevedo y Adam de la Parra», Boletín de la Real Academia de la Historia, 169, 1972, pp. 171-182.

Ettinghausen, Henry, “Ideología intergenérica: la obra circunstancial de Quevedom, en Estudios sobre Quevedo. Quevedo desde Santiago entre dos ani- 
versarios, coord. Santiago Fernández Mosquera, Santiago, Universidad de Santiago de Compostela, 1995, pp. 225-259.

Fasquel, Samuel, «Entre plaidoyer et consolation: La caída para levantarse de Quevedom, e-Spania, en ligne, 18, mis en ligne le 01 juin 2014, consulté le 29-4-2017, URL: http://e-spania.revues.org/23528

Grilli, Giuseppe, «Quevedo y la polémica rebelión catalana. Una reflexión sobre la racionalidad y el irracionalismo en la ciencia política), La Perinola, 18, 2014, pp. 77-103.

Jauralde, Pablo, «Obras de Quevedo en la prisión de San Marcos», Hispanic Review, 50, 1982, pp. 159-171.

Jauralde, Pablo, Francisco de Quevedo. 1580-1645, Madrid, Castalia, 1999.

Martínez Millán, José, «Reflexiones en torno a los escritos políticos e históricos de Francisco de Quevedo», La Perinola, 18, 2014, pp. 103-141.

Nider, Valentina, «Nerón y el arquitecto: sobre una variante quevediana acerca de la caída de Olivares», en Quevedo en Manhattan, ed. Ignacio Arellano y Victoriano Roncero, Madrid, Visor Libros, 2004, pp. 189-204.

Pellicer de Tovar, José, Avisos, ed. Jean Claude Chevalier y Lucien Clare, Paris, Éditions Hispaniques, 2002.

Pérez Cuenca, Isabel y Manuel Urí Martín, «El escritor y el valido: de las garras del león a los cuernos del toro», Hesperia. Anuario de Filología Hispánica, iv, 2001, pp. 102-114.

Pérez Cuenca, Isabel, y Mariano de la Campa, «El Conde Duque de Olivares, Quevedo y otros contemporáneos», Librosdelacorte.es, 5, año 4, otoño-invierno, 2012, pp. 121-123.

Quevedo, Francisco de, Carta al serenísimo, muy alto, y muy poderoso Luis XIII, rey cristianísimo de Francia, ed. Carmen Peraita, en Obras completas en prosa, dir. Alfonso Rey, vol. III, Madrid, Castalia, 2005, pp. 249-305.

Quevedo, Francisco de, La caída para levantarse, ed. Valentina Nider, Pisa, Giardini, 1994.

Quevedo, F. de, Memorial que escribió don Francisco de Quevedo al Conde Duque, ed. Alfonso Rey, en Obras completas en prosa, dir. Alfonso Rey, vol. vi, Madrid, Castalia, 2015, pp. 380-392.

Quevedo, F. de, Memorial de don Francisco de Quevedo suplicando su soltura de la prisión que padecía en San Marcos de León, ed. Alfonso Rey, en Obras completas en prosa, dir. Alfonso Rey, vol. vi, Madrid, Castalia, 2015, pp. 395-403.

Quevedo, Francisco de, Nuevas cartas de la última prisión de Quevedo, ed. James O. Crosby, Rochester / New York, Tamesis Book, 2005.

Quevedo, Francisco de, Panegírico a la majestad del rey nuestro señor don Felipe $I V$, ed. Alfonso Rey, en Obras completas en prosa, dir. Alfonso Rey, vol. III, Madrid, Castalia, 2005, pp. 473-495.

Quevedo, Francisco de, Política de Dios, ed. James O. Crosby, Madrid, Castalia, 1966.

Quevedo, Francisco de, La Rebelión de Barcelona ni es por el güevo ni es por el fuero, ed. Manuel Urí, en Obras completas en prosa, dir. Alfonso Rey, vol. III, Madrid, Castalia, 2005, pp. 433-471.

Quevedo, Francisco de, Respuesta al manifiesto del Duque de Berganza, ed. M. ${ }^{a}$ Soledad Arredondo, en Obras completas en prosa, dir. Alfonso Rey, vol. III, Madrid, Castalia, 2005, pp. 371-431.

Rey, Alfonso, «Los memoriales de Quevedo a Felipe IV», Edad de oro, XII, 1993, pp. 257-265. 
Rey, Alfonso, “La construcción crítica de un Quevedo reaccionario», Bulletin hispanique, 112, 2, 2010, puesto en línea el 05 de enero de 2014, consultado el 09 de septiembre de 2015.

Rey, Alfonso, «Introducción» a Francisco de Quevedo, Obras Completas en prosa, dir. Alfonso Rey, vol. vi, Madrid, Castalia, 2015, pp. IX-XLvıII.

Saavedra Fajardo, Diego, Suspiros de Francia, ed. Belén Rosa de Gea, en Rariora et minora, Murcia, Tres Fronteras, 2008, p. 379-391.

Saavedra Fajardo, Diego, Empresas políticas, ed. Sagrario López Poza, Madrid, Cátedra, 1999.

Sánchez Sánchez, Mercedes, Cartas de Francisco de Quevedo a Sancho de Sandoval (1635-1645), Madrid, Calambur, 2009. 



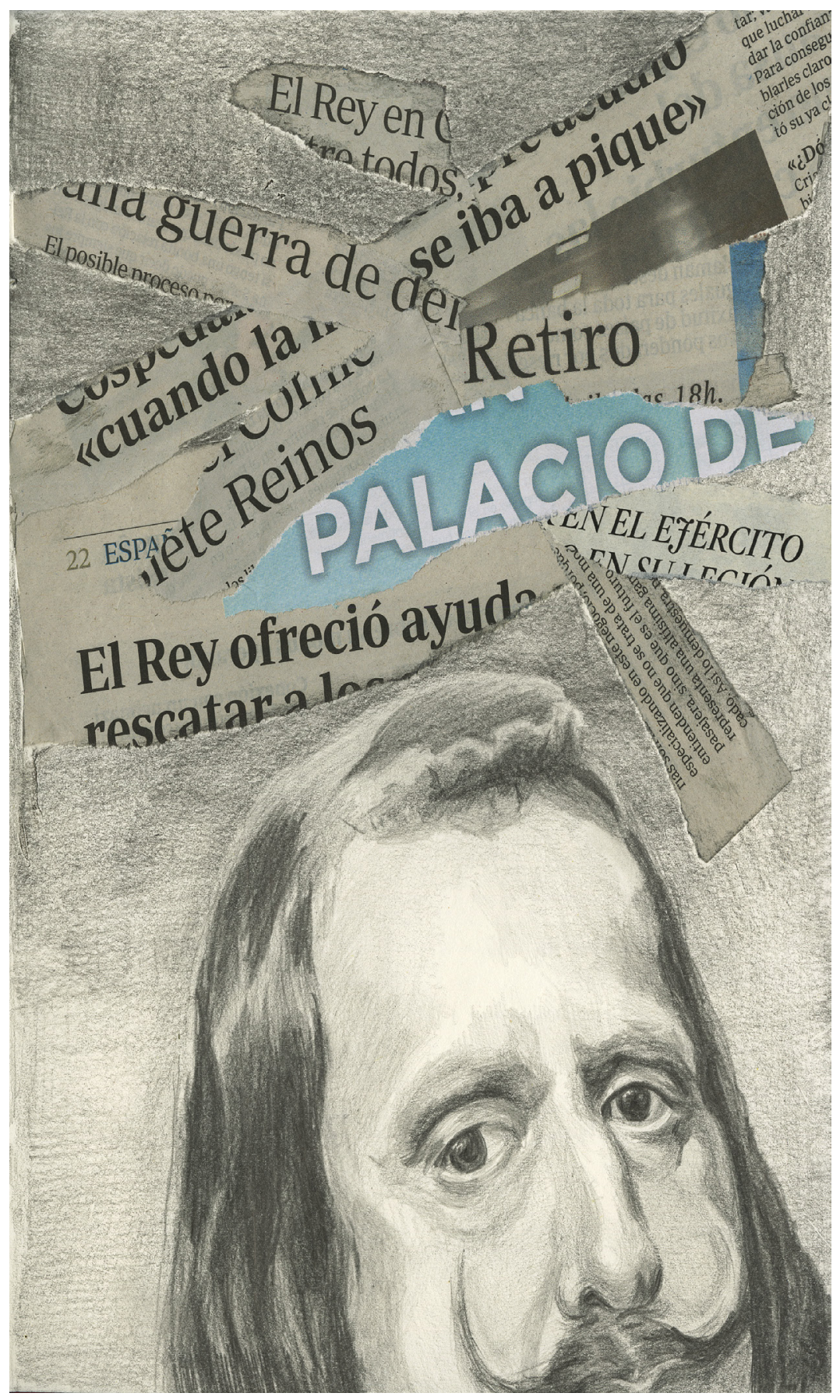


